\title{
Crónica sentimental del fútbol
}

\author{
JORDI OSÚA QUINTANA
}

\section{Fútbol, historia y memoria}

En la figura de Manuel Vázquez Montalbán confluyen una gran afición futbolística y un fuerte compromiso político. Una coincidencia original porque, con frecuencia, se entiende el fútbol, en particular en su versión espectáculo, como un simple entretenimiento cuyo objetivo principal es evadir al espectador de los problemas cotidianos. Y, a su vez, el activismo político, sobre todo durante la segunda mitad del siglo pasado, recela del fútbol por considerarlo un opio muy eficaz en la manipulación de las masas.

Este no es el caso de Montalbán. En su extensa obra no elude sus aficiones particulares ni, por supuesto, el fútbol, al que dedicó más de 400 textos. A través de su quehacer literario, generó un pensamiento futbolístico que, lejos de valorarlo como un simple pasatiempo, lo entiende como una manifestación de la cultura popular digna de ser estudiada.

En los círculos ilustrados europeos, el fútbol despertaba enormes suspicacias. No olvidemos la descarada instrumentalización del Campeonato del Mundo de Italia (1934) en aras de la propaganda mussoliniana. El fútbol, en cuanto espectáculo de masas, actuaba como un poderoso agente alienador, un opio de un pueblo que, sumido en el delirio colectivo, desatendía su responsabilidad en la configuración del proceso histórico.

Vázquez Montalbán suscribe esta idea y no duda en arremeter contra la manipulación política a la que las autoridades franquistas someten al deporte que más atención despierta en España. Consciente de esta instrumentalización, utiliza la expresión "Pan y fútbol" ("Barça! Barça! Barça!”, 26), siguiendo el título de un artículo publicado por José María Pemán en ABC, que a su vez parafrasea el Panem et circenses de Juvenal. El fútbol es un entretenimiento que distrae de los auténticos conflictos políticos y sociales.

Aun así, el escritor barcelonés no desdeña este deporte ni se conforma con una simple visión crítica. Desde su conocimiento directo, plantea nuevos escenarios de interpretación. Su interés por el fútbol obedece a la voluntad de rescatar del olvido un pasado conflictivo, una necesidad política. Los vencedores reescriben la historia. La damnatio memoriae, la condena de la memoria no es una simple represalia, es una estrategia 
de dominación que, tal como mostró Orwell en 1984, altera de manera arbitraria el relato que sustenta una sociedad. De este modo, Montalbán sintoniza con el pensamiento de Walter Benjamin al abordar el fútbol desde la perspectiva de la memoria histórica:

Articular históricamente el pasado no significa conocerlo "tal como verdaderamente fue". Significa apoderarse de un recuerdo como este relumbra en el instante de un peligro. De lo que se trata para el materialismo histórico es de atrapar una imagen del pasado, tal como esta se le enfoca de repente al sujeto histórico en el instante de peligro. El peligro amenaza tanto a la permanencia de la tradición como a los receptores de la misma. Para ambos el peligro es uno y el mismo: de entregarse como instrumentos de la clase dominante. En cada época es preciso hacer nuevamente el intento de arrancar la tradición de manos del conformismo, que está siempre a punto de someterla (Benjamin 2008, 40).

Vázquez Montalbán descubre en el fútbol, convertido en un fenómeno de la cultura de masas, una fuente relevante de información que, en vez de alejarnos de los hechos reales, nos sumerge en la sentimentalidad popular. El fútbol español de mediados del siglo XX transmitía una narrativa en la que los éxitos en el terreno de juego, aderezados con ribetes historicistas, renovaban las victorias en los campos de batalla $y$, a su vez, reforzaban la vivencia subjetiva de la derrota.

En este contexto, reivindica una memoria subversiva, la recuperación del pasado para construir un discurso emancipador gestado en una narración histórica libre de injerencias manipuladoras. Montalbán nos aporta unas memorias, una historia crítica, una visión subjetiva en la que lugares, fechas y protagonistas se integran en una trama más compleja que trasciende la esfera puramente futbolística. En sus análisis supera la curiosidad por lo puramente técnico para captar cómo aflora en los partidos la trama invisibilizada de las tensiones políticas y sociales. Al percibir el microcosmos futbolístico como un laboratorio social, Montalbán vuelve a coincidir con el pensamiento del filósofo berlinés:

Al jugar los niños, rodeados por un mundo de gigantes, crean uno pequeño que es adecuado a ellos, mientras que el adulto, rodeado por la amenaza de lo real, le quita al mundo su horror haciendo de él una copia reducida (Benjamin 2006, 470). 
Para Vázquez Montalbán el fútbol expresa ese juego simbólico, esa copia reducida del mundo, donde los adultos pueden plantear los conflictos reales mientras son vigilados por los gigantes del poder. Rastreando entre la prolífica obra montalbaniana, hallamos suficiente material para articular una crónica sentimental del fútbol, una amalgama de reflexiones, recuerdos, vivencias e ilusiones que se entretejen a partir del hilo conductor de la competición nacional. Esta crónica es el relato de cómo un fenómeno estrictamente deportivo refleja las vicisitudes sociales y políticas de su época y afecta a una sentimentalidad compartida.

Como miembro de una clase social que no dispone de personas con la formación necesaria para expresar sus vivencias, Montalbán asume la responsabilidad de hacer presente este universo cultural "oculto" para una gran parte de la sociedad española:

Pero más que recuperar aquel mundo, tengo un cierto sentido de culpa cuando pienso que aquella gente, que poseía una existencia personal e intransferible, vivencias y emociones como cualquier ser humano, no tiene, normalmente, nadie que explique qué les pasó. No han tenido un lenguaje ni la posibilidad de construir su épica. Yo soy uno de ellos y, en cambio, he llegado a unos niveles en que puedo explicar y reflejar todo esto. Y sí que tengo esta responsabilidad (Aranda 1995, 20-21).

La restitución de la memoria, tanto histórica como cotidiana, se convertirá en una de las formas de expresar su disconformidad con la realidad e intentar transformarla. Daniel Vázquez destaca que su padre reivindicaba la memoria y despreciaba la nostalgia al considerarla un ejercicio censurador de la primera ("Manuel Vázquez Montalbán: el fabulador de la memoria", p. xi). Pese a esta devoción por los recuerdos, el escritor barcelonés reconoce sus límites como instrumento para explicar la realidad. La película "Rashomon" de Kurosawa, que vio por primera vez en un cine de barrio en su adolescencia, le ayudó a comprender la insuficiencia de la memoria para acceder a la verdad (Crónica del desencanto, 283). Por eso considera la memoria, como propuesta literaria, una "deshonestidad intermedia" (Barcelonas, prólogo).

No obstante, la revisión del pasado se convertirá en una herramienta imprescindible para el método de crónica documentada empleado por primera vez en el artículo "Crónica sentimental de España". Un estilo periodístico novedoso que impresionó a sus lectores. En el fondo, Vázquez Montalbán solo puede encontrarse a sí mismo en la "ciudad de 
la memoria", asumiendo el riesgo de autoengaño concomitante con los recuerdos:

Ahí hay una serie de análisis de las ciudades posibles, desde los materiales a las espirituales, desde las metafísicas a las históricas, la ciudad del bien, la ciudad del mal, la ciudad del recuerdo, la ciudad del deseo... todo eso con un reconocimiento final de que el único éxito lo encontramos en la ciudad de la memoria, porque es en ella donde podemos falsificar y mistificar y manipular una experiencia que a lo mejor no ha existido (Tyras 2003, 235).

\section{La reconciliación con el fútbol en la prisión de Lérida}

En 1956, Vázquez Montalbán inicia sus estudios en la Facultad de Letras de la Universidad de Barcelona. Es la primera vez que abandona su entorno inmediato traspasando los límites de su barrio y su ambiente social formado por trabajadores inmigrados y catalanes para encontrarse mayoritariamente con miembros de la burguesía de la ciudad (Què pensa Manuel Vázquez Montalbán, 33). La entrada en contacto con gente de otras clases sociales comporta un aspecto positivo y otro negativo para el joven procedente del Raval. Vázquez Montalbán queda gratamente sorprendido al ver que puede compartir sus ideas políticas con personas socialmente alejadas de su realidad, pero comprometidas en actos antifranquistas. Pero, por otro lado, la diferencia respecto a sus hábitos culturales y lúdicos constituye un abismo difícil de superar:

El encuentro con gente que sus modos de vivir y educación en sus aspectos vivenciales no tenía nada que ver conmigo fue bastante duro en cuanto a comunicación. No en los aspectos intelectuales donde había sintonía sobre todo con los grupos que estaban en la clandestinidad contra el franquismo, sino en aspectos muy vitales, en cómo se pasaban las tardes, qué referencias de carácter lúdico tenían, qué cultura de sustrato popular tenían ellos y cuál yo (ACEC 2003).

Este desajuste le lleva a dejar de lado algunos de los rasgos más propios de su educación sentimental, como el fútbol. Una afición considerada una frivolidad por el pensamiento marxista dominante en el ambiente universitario del momento:

Luego, al ingresar en la Universidad me entró una especie de purismo raquítico-intelectual de no transigir con mis veleidades alienantes, como podía 
ser el fútbol y el roscón de Reyes. Dejé de frecuentar el estadio durante unos años ("Barça, Barça, Barça", 1971).

En abril de 1962 la vida de Manuel Vázquez Montalbán da un vuelco inesperado. Debido a los informes previos, es detenido y condenado a tres años de prisión por participar en la manifestación convocada en Barcelona para solidarizarse con los mineros de Asturias. Esta experiencia no solo condicionará su vida profesional, tendrá muchas dificultades para encontrar trabajo al retirársele el carné de periodista y tener antecedentes penales, sino también su vida intelectual. En la cárcel realizará una síntesis entre su cultura universitaria y popular que determinará tanto su reflexión intelectual posterior como su estilo periodístico y literario.

Tras ser juzgado por un tribunal militar permanece durante sus primeros días de encarcelamiento en la Modelo de Barcelona. Luego es trasladado a la prisión de Lérida donde comparte celda con Salvador Clotas, de letras, Ferran Fullà, físico, y Martí Capdevila, economista. Cada uno disponía de una celda propia, pero durante el día se juntaban en la de uno de ellos para hablar. Vázquez Montalbán valora este periodo, y en especial las conversaciones con Salvador Clotas, como una etapa mucho más formativa que la universitaria. Una época donde pasaba sus años de estudio más centrado en la lucha política que en la vida académica:

Fue muy importante. Representó la posibilidad de hablar y de leer de una manera frenética, de discutir, de opinar, de darle en seguida lo que yo escribía y él me lo opinaba; era un chico con gran criterio literario (Erba).

Además, debido a algunos encargos editoriales y a contactos con los responsables de la cárcel, pudo conocer el pensamiento de algunos autores que serán decisivos en un futuro, como el escritor Cesare Pavese o Antonio Gramsci, Secretario General del Partido Comunista Italiano. Unas lecturas que, según la opinión de Salvador Clotas recogida en la tesis de Francesc Salgado, le alejaron de la ortodoxia marxista (94). Los meses en la prisión rodeado de libros y de otros intelectuales de diferentes áreas del saber le permiten recuperar una parte de la vida que había dejado de lado en la universidad:

Todo aquello [la ausencia de gente de origen obrero en la universidad] provocó que yo, en parte, ocultase un poco mis raíces. No lo hice por vergüenza de mi procedencia, sino porque me veía delante de un nuevo reto. En la prisión, en cambio, todo esto se sedimentó. En cierta manera, podría decir que 
me reconcilié con mi pasado. Hice, digámoslo así, la síntesis entre mi background de carácter popular y mi formación como universitario y me salió esta escritura mestiza, esta escritura de la mezcla (Aranda 1995, 46).

Esta reconciliación con su pasado es básica para comprender su interés intelectual por el fútbol, un elemento propio de su educación sentimental y de su cultura de barrio, y la aplicación del método subcultural al análisis de este deporte. En el prólogo del libro Barça, Barça, Barça. FC Barcelona, esport $i$ ciutadania publicado en 1972, Vázquez Montalbán explica quiénes pueden llevar a cabo esta aproximación científica: personas que hayan crecido en el marco de una cultura de barrio en los años cuarenta y cincuenta y, a su vez, hayan adquirido la formación académica necesaria. Una afirmación que puede aplicarse perfectamente al propio periodista barcelonés y debe situarse en este periodo penitenciario:

Precisamente, el interés serio hacia el terreno subcultural proviene de la llegada a la universidad de estudiantes que proceden del proletariado o de la pequeña burguesía, de estudiantes a caballo entre la Subcultura y la Cultura Sacramental. De este enfrentamiento han surgido algunos esfuerzos clarificadores de síntesis entre los que destaca, sin duda, el trabajo admirable de Artells (9-10).

Tras salir de la cárcel recupera la creencia en sus mitos futbolísticos y en el FC Barcelona, su club de la infancia, y opta por reservar su comprensión racional del mundo para la reivindicación política:

Cuando salí de tan extraño club (la cárcel), pasé un periodo de descreimiento futbolístico, hasta que me planteé: ¿qué es más estúpido, creer en Basora, César, Kubala, Moreno y Manchón o en Carrillo y el Guti? Decidí creer en el Barça y estudiar muy de cerca la política que me afectaba, pero siempre, siempre, desde la evidencia de que ni la historia, ni la vida, ni Europa eran como nos las merecíamos ("Credo", 54).

Al fin y al cabo, la militancia política podía ser tan "alienante" como la futbolística:

Yo respondo siempre a eso con unos versos de Brecht que me impresionaron mucho. Los leía en la cárcel cuando tendría unos veintitrés años, y son los dos primeros versos de la "Oda al Partido": "Tienes dos ojos / pero el Partido tiene mil". No hay duda de que Brecht lo escribió primando la mirada 
colectiva sobre la mirada individual. Con el paso de los años, he pensado que se podría invertir la fórmula: "Aunque el Partido tenga mil ojos / siempre debes conservar los dos tuyos". Si no, se cae en la militancia religiosa, que es la que ha destrozado el socialismo real (Tyras 2003,31).

Las primeras manifestaciones de esta valoración del fútbol como parte de la cultura de masas de un país y como expresión de una sentimentalidad popular se concretan en tres trabajos periodísticos. El primero, en 1965, la elaboración de un artículo sobre las actividades propias del domingo en las clases populares titulado "Domingo nunca es domingo". El segundo, en 1966, la redacción de la serie "Crónica sentimental de España", una historia social del país desde los años cuarenta donde aparece el fútbol como una fuente donde saciar la necesidad épica de un pueblo que vive en situación de extrema pobreza y como un instrumento para su control por parte del franquismo. Y, finalmente, en 1969, el "Barça! Barça! Barça! donde explica el simbolismo y la representatividad del F. C. Barcelona como un elemento de identificación e integración para los inmigrantes en Cataluña.

\section{El fútbol en la "Crónica sentimental de España"}

El retorno a la práctica periodística supone un proceso largo y costoso. Hasta la publicación de la "Crónica sentimental de España", Vázquez Montalbán no encuentra la estabilidad profesional. Tras la aventura de la revista Siglo 20 iniciada en 1965 y finalizada unos meses después como consecuencia de la censura informativa, el periodista barcelonés no dispone de ningún medio impreso donde expresarse con regularidad. Pese a ello, mantiene firme su voluntad de recuperar la cultura popular. La elaboración de un guión sobre una serie de artículos titulada "Crónica sentimental de España" debe situarse cronológicamente en el año 1966 (Los pseudónimos de Vázquez Montalbán, sin paginar).

En el verano de 1969, aprovechando la ausencia de los colaboradores habituales y la relación con los nuevos redactores de la revista TriunfoCésar Alonso de los Ríos, compañero de trabajo en Siglo 20, y Víctor Márquez-, recibe el encargo de desarrollar una serie de cinco artículos. ${ }^{1}$

\footnotetext{
${ }^{1}$ Curiosamente su último artículo publicado en El País poco antes de su muerte trataba sobre la revista Triunfo, cerrando así el círculo iniciado en 1969. Fuente: Vázquez Montalbán, Manuel. “Triomf”. El País [Barcelona]. 13 Octubre 1990: última página.
} 
Una crónica, según el propio autor, escrita desde la memoria más personal:

Yo estaba en un apartamento alquilado en la Costa Brava. No disponía de un apunte, ni de un libro, siquiera un cancionero, pero sí de la sensación de que pasaba ante mi puerta una oportunidad soñada durante muchos años. De memoria, de la más angustiada memoria saqué todos los recuerdos válidos para escribir cuatro capítulos y cuando los envié me reclamaron dos más ( $L a$ literatura en la construcción de la ciudad democrática, 134).

Esta crónica refleja una visión muy particular de la historia cotidiana de España en los años cuarenta, cincuenta y sesenta. El propio Vázquez Montalbán explica qué pretendía al elaborar esta serie de artículos:

Explicar las claves de la educación popular posterior a la Guerra Civil, a través de los aparatos educacionales e informativos del franquismo, de los materiales entonces llamados subculturales o paraculturales: canciones, mitos y símbolos promovidos por los medios de comunicación, asumidos por la sabiduría convencional, tratando de ofrecer la atmósfera de aquellos años de falsificación del lenguaje, de la historia, de la memoria del vencido, de la consciencia, es decir, incluso de la falsificación del saber acerca de la realidad y nuestra inserción en ella (La literatura en la construcción de la ciudad democrática, 133).

El fútbol ofrecía algunos de estos mitos y símbolos que a través de los medios de comunicación habían educado sentimentalmente a las clases populares falseando la realidad. En el segundo artículo de la serie dedicado a los años cincuenta, "Casi todo en technicolor", explica el origen de la épica nacional futbolística. Una connotación política atribuida a la selección española tras su actuación en la fase de clasificación y en la fase final del Mundial de Brasil (1950) y fomentada por las retransmisiones radiofónicas de Matías Prats:

Pero sin épica no es posible la vida, y si no hay épica, hay que inventarla. Allí estaba el inventor, tras sus gafas oscuras, con el acento andaluz encerrado en la camarilla que hay debajo de la lengua, con voz de barítono, con bigotillo de director general. El inventor de la principal corriente épica nacional se llamaba Matías Prats (32). 
A partir de esta gesta deportiva, el fútbol alcanzará un protagonismo que hasta entonces no había tenido. Con el paso de los años se acabará convirtiendo en un elemento fundamental para garantizar la felicidad de las masas, sobre todo los domingos:

Meses después de la vuelta de la selección, se proyectó en todo el territorio nacional un documental sobre la gesta de la selección española. Llevaba un título de diario español de provincias o de documento izquierdista de intelectuales sartrianos. Se llamaba "La Verdad". (...) Y después de la Verdad de Río, el fútbol protagonizó los domingos (32-33).

En la tercera entrega de la Crónica, "Cuando Di Stéfano y Kubala llenaban los estadios", Vázquez Montalbán analiza el papel fundamental que tendrá la llegada de estos grandes jugadores para el resurgimiento del fútbol español durante los años cincuenta. Unos mitos que forman parte de su mestizaje cultural (Crónica del desencanto, 284) y cuya popularidad los llevará incluso a protagonizar películas. Las contínuas genialidades de estos futbolistas ayudaron a promocionar este deporte entre los ciudadanos, iniciándose así la alienación futbolística:

Todos estos equipos crearon la necesidad urgente de ir al fútbol para admirar las continuas genialidades de Kubala, el don de improvisación de Faas Wilkes o la maestría constructora de Alfredo Di Stéfano. Nadie comprendió cómo en juego tan maravillosos jugadores, España fuera eliminada para los Campeonatos del Mundo de 1954 y 1958. Estos resultados se compensaban con los éxitos del Barcelona en la Copa Latina o del Madrid en la Copa de Europa. La alienación futbolística era un hecho, un hecho que molestaba distanciadamente a José María Pemán, que en las páginas de ABC se descolgó con un artículo llamado "Pan y fútbol", evidencia, una vez más, de la maestría de Pemán en hacer ver que critica algo, cuando en realidad está dispuesto a concordar con todo (34).

En este capítulo Montalbán achaca, por primera vez, la acentuación de la rivalidad futbolística, histórica y política entre Barcelona y Madrid después de la Guerra Civil al conflicto derivado del fichaje de Di Stéfano primero por el "Barça" y posteriormente por el Real Madrid (34-35). Una polémica vivida en su adolescencia que quedó grabada para siempre 
en su memoria. Era el verano de 1953 y tenía catorce años. ${ }^{2}$ La resolución favorable a los intereses del club blanco de esta disputa futbolística se percibe como un agravio más del franquismo contra los catalanes. El periodista barcelonés asume el sentimiento de la sociedad catalana, convencida de que el franquismo trasladaba el conflicto político al terreno futbolístico. Asimismo, atribuye el resultado final de la negociación, marcado por la renuncia del "Barça", a las presiones que recibe su presidente y a la intervención de la Federación Española de Fútbol controlada por el régimen:

Todas las autoridades deportivas visibles o invisibles propusieron que el Barça y el Real Madrid compartieran a Di Stéfano, un año en el Barça, otro en el Madrid, y mientras tanto el presidente del Barcelona empezó a recibir presiones, insinuaciones, amenazas, intervenciones en sus negocios y el club tiró a Di Stéfano por la ventana, con la garganta llena de congojos, y en la calle la indignación de la todavía no llamada sociedad civil que sumó el robo de Di Stéfano a los excesos del franquismo ("Di Stéfano, Kubala, Suárez", 51).

Incluso, pese a ser consciente que se trata de una exageración, Vázquez Montalbán llega a definir esta voluntad de favorecer al Real Madrid y perjudicar al "Barça" por parte del aparato franquista, de la que el affaire Di Stéfano constituye una prueba irrefutable, como "ocupación futbolística". Esta nueva modalidad de "ocupación" se sumaba a la lingüística, cultural y militar que los engranajes del Estado central habían tratado de ocultar a todos los habitantes de Cataluña, incluido él mismo. Despertar la conciencia de esta identidad catalana y denunciar su opresión por parte del franquismo a través del fútbol será, a partir de este momento, uno de sus objetivos:

Cuando yo era un niño inmigrante los aparatos del Estado central trataron de ocultarme que había nacido en un país que tenía una lengua propia, una cultura, una historia. Adquirí conciencia de ello por mi cuenta, en una calle empapada de agravios, escasamente burgueses en mi barrio, contra el oscuro o-

\footnotetext{
${ }^{2}$ La inclusión de este suceso en el último artículo deportivo publicado poco antes de su muerte, con motivo del 50 aniversario de la llegada del jugador argentino a España, demuestra la impronta que dejó en su vida. Vázquez Montalbán, Manuel. "Di Stéfano, Kubala, Suárez...". El País [Barcelona] 22 Septiembre 2003: 51 .
} 
rigen de la ocupación lingüística, futbolística y militar de Cataluña. Y ese origen se llamaba Madrid ("Los tradicionales lazos de enemistad", 81).

Finalmente, en el cuarto artículo de la serie, "Los felices sesenta", Montalbán recuerda la utilización política que el franquismo realizó del triunfo logrado por la selección española en el Campeonato de Europa de 1964:

El fútbol nacional volvía a ofrecer una oportunidad para exhibir las bondades del régimen franquista al resto de Europa. En 1964, España se convierte en campeona de Europa de fútbol, gracias a la derrota de la URSS en Madrid. Es nuestro hito más importante, después de las últimas victorias de nuestros tercios en la guerra de los Treinta Años (38).

Un éxito consagrado por Matías Prats a la celebración de los veinticinco años del final de la Guerra Civil:

Prats siempre ha sabido hallar el correlato histórico totalizador que corresponde al hecho deportivo. No. No ha sido un locutor lineal, positivista, neopositivista, ¡ni siquiera neopositivista! Ha sido un locutor dialéctico, que, por ejemplo, cuando España ganó a la URSS en Madrid en 1964, ofrendó aquel triunfo a la conmemoración de los XXV Años de Paz ("Casi todo en technicolor, 33).

La Crónica, además de denunciar la utilización franquista del fútbol, le permite reivindicar su relevancia como parte de la cultura popular del país. En este sentido, Vázquez Montalbán tiene el mérito de romper con una cierta "mala conciencia" de la izquierda progresista consistente en mirar sospechosamente el gusto por algunos aspectos subculturales considerados reaccionarios como la copla o el fútbol. Miguel Ángel Villena inicia así un artículo dedicado a presentar su libro póstumo Fútbol. Una religión en busca de un dios:

Un marxista convicto y confeso como Manuel Vázquez Montalbán demostró hace ya tres décadas, desde las páginas de la revista Triunfo, que la afición por el fútbol no estaba reñida con la militancia antifranquista ni con las inquietudes intelectuales ni tan siquiera con la memoria sentimental de la infancia ("Mucho más que deporte", 13). 
En esta serie de artículos empieza su particular lucha contra la visión tradicional de la izquierda marxista que considera el fútbol como un opio para el pueblo y la reivindicación de su papel en la configuración y expresión de la sentimentalidad de las clases populares. El historiador y crítico literario Joaquim Molas constata como la intelectualidad en general, mucho antes de los años sesenta, rechazaba el fútbol por tratarse de un deporte "vulgar", en el sentido de popular, y por el lenguaje de la prensa deportiva:

Con el fútbol pasó, y no solo en la década de los sesenta, que enseguida los intelectuales se sintieron un poco incómodos por el hecho de ser un deporte de masas, que a los ojos de muchos lo hace inevitablemente vulgar, con el agravante que arrastra por sí mismo una literatura elaborada por la prensa deportiva que les obliga a distanciarse de él (Espadaler 1999, 8).

A partir de ese momento, el escritor barcelonés aprovecha la escritura sobre fútbol, donde la censura era más liviana, para insistir en el asalto a la llamada "contradicción de primer plano": el franquismo. Contrariamente a lo que defendía la clase política española, Vázquez Montalbán no cesará en su intención de mezclar política y fútbol como un medio para poner al descubierto las manipulaciones y los engaños del régimen. Así lo reconoce él mismo: "Yo no he hecho otra cosa que utilizar mi escritura para denunciar la asfixia dictatorial en la cual me hicieron nacer" ("La memòria històrica", C2). Unos años más tarde expresa claramente esta posibilidad que ofrecía la crónica futbolística para concienciar a los lectores de los problemas políticos y sociales del país:

Sería lastimoso, porque hoy por hoy, gracias a la crítica de fútbol, de política municipal y del Presidente Nixon, vamos cumpliendo los periodistas con nuestra mala conciencia por las impotencias críticas e informativas que mis lectores, a los que tanto quiero y que tanto me quieren, me harán el favor de suponer ("Lo intocable y lo innombrable", 10).

En octubre de 1969, escribe un artículo donde se amplían algunos de los temas apuntados en "Cuando Di Stéfano y Kubala llenaban los estadios". Se trata del famoso "Barça! Barça! Barça!", título precedido por una expresión reveladora de su sentido: "más allá del fútbol". Un texto donde se explican las claves históricas y sentimentales que habían convertido al "Barça" en "algo más que un club" para sus seguidores. En esta pieza periodística desarrolla más extensamente la relación entre los 
agravios futbolísticos y políticos entre Barcelona y Madrid; expone las reticencias del régimen franquista hacia un club alineado con la República durante la Guerra Civil y con la burguesía nacionalista; y relaciona la identificación del inmigrado con el club a su voluntad de adaptarse a la cultura catalana. ${ }^{3}$

En "Barça! Barça! Barça!", presenta el club como un médium deportivo que establece una relación con el público por encima de la victoria o de la derrota. El Barça constituye uno de los últimos reductos donde se mantiene intacta la identidad catalana, convirtiéndose en un instrumento que comunica al aficionado con la historia de Cataluña. Por este motivo, actúa como un vehículo de integración al país. Así sucedió con su fundador, un suizo conocido como Joan cuya catalanidad nadie discutía en los años veinte. Este carácter identitario, político y social transforma al "Barça" en un elemento más de concienciación que de alienación política: "En casos como el Barcelona, el fútbol ha conseguido efectos completamente contrarios a los propósitos" (26).

Esta crónica del barcelonismo tuvo una gran aceptación entre algunas de las personalidades y de las instituciones catalanas más significativas, tanto políticas como culturales:

A partir de la publicación en la portada de Triunfo del "Barça, Barça, Barça", me escribieron adhesiones desde monjes de Montserrat hasta aspirantes a secretarios generales del PSUC e intelectuales autoexiliados en París, así como Oriol Bohigas y Salvador Espriu, cartas que recibí como si fueran un salvoconducto vitalicio para todas las galaxias de la catalanidad ("Tot el camp és un clam", 21).

En una carta publicada en la misma revista Triunfo, uno de los lectores, catalán residente en Madrid, explica el impacto emocional que le supuso su lectura:

Puedo asegurar que nunca he leído una cosa tan emocionante y tan bien hecha como el artículo Barça, Barça, Barça del señor Vázquez Montalbán. Después de haber leído el citado artículo del señor Montalbán, me he expli-

\footnotetext{
${ }^{3}$ La inclusión de este artículo dentro de una antología publicada por El País el verano de 1995 demuestra su importancia histórica y periodística. Sagarra, Joan y Espada, Arcadi. "Antes de todo esto. Una antología de textos periodísticos (1966-1981)”. El País, Cataluña [Barcelona] 2 Agosto 1995: 2.
} 
cado a mí mismo muchas cosas que yo sentía de una manera que me parecía inconsciente. $^{4}$

Vázquez Montalbán también tuvo un protagonismo destacado en la elaboración de una de las obras más importantes para la recuperación de la identidad política y social del barcelonismo. Me refiero al libro Barça, Barça, Barça. F. C. Barcelona, esport i ciutadania, escrito por Joan Josep Artells. El propio autor reconoce que el título constituía un homenaje al artículo de Montalbán publicado en Triunfo. Fruto de la relación tan estrecha con Artells, Montalbán escribió el prólogo del libro, un texto donde expone algunas de sus ideas respecto al valor subcultural de la afición barcelonista. En primer lugar, valora la importancia de abordar un tema de la cultura de masas como la pertenencia a un club de fútbol. Una aportación necesaria para, en contra de la idea generalizada entre los pensadores de izquierdas, evitar su manipulación por parte del poder.

También reivindica esta aproximación subcultural como la más adecuada si se quiere comprender el significado que este club ha tenido a lo largo de la historia del pueblo catalán como medio de expresión de su sentimentalidad. Una historia incomprensible si se desvincula de la historia de España y de Cataluña. La trayectoria del club evidenciaba como, antes de la Guerra Civil, ya representaba la posición política de la burguesía catalana y, posteriormente, la única forma de expresión identitaria para todo un país (7).

Asimismo, considera que este trabajo arqueológico de búsqueda de los restos de la subcultura del pueblo catalán en la historia del Barça debe ser valorado en su justa medida. Una aportación novedosa ya que hasta ese momento nadie había abordado con seriedad estas cuestiones, y menos aún desde un punto de vista científico. Insiste respecto al engaño de las actitudes "campistas" 5 que ocultan, detrás de su aparente generosidad para acudir al rescate de la subcultura, una postura inicial de rechazo y, en el fondo, no permiten un conocimiento real de los hechos sub$-$

${ }^{4}$ Carta publicada en la página 42 de la revista Triunfo el día 1 de noviembre de 1969.

${ }^{5}$ Susan Sontag popularizó este concepto en su obra Contra la interpretación (1964). Vázquez Montalbán se refiere así al sentido de esta expresión en un artículo publicado en la revista Triunfo: "El camp es también, como dice la Sontag, un tierno sentimiento, un cierto franciscanismo visual con el que el intelectual puede contemplar los restos de todo tipo de batallas: temporales, históricas, personales, sentimentales". Vázquez Montalbán, Manuel. "De la kulturkampf a la culturcamp". Triunfo [Madrid] 20 Diciembre 1969: 35. 
culturales. También se reafirma en su defensa de la subcultura, una verdadera cultura perteneciente al pueblo que, pese a su manipulación por parte del sistema, es tan válida como cualquier otra. Por eso, lo más importante de esta obra no es el resultado, sino su función pionera para despertar la conciencia sobre la necesidad y la importancia de estudiar con rigor, utilizando los instrumentos científicos adecuados, los temas subculturales (7-8).

\section{La memoria futbolística del franquismo}

\section{La voz de Matías Prats}

La radio fue el medio de comunicación escogido para imponer una conciencia nacional en el Estado español. El locutor Matías Prats fue el encargado de llevar a cabo esta misión a través del fútbol. Desde los años cuarenta, consiguió que las gestas futbolísticas formaran parte de la historia de la nación española. Matías Prats ensalzaba las cualidades de los futbolistas españoles y gritaba con fuerza cuando España marcaba un gol. Las emociones que transmitía convencían al público de la superioridad del juego del combinado nacional. Al finalizar el partido nadie entendía cómo había sido posible la derrota. Esta percepción desproporcionada del valor futbolístico de la selección española facilitó su instrumentalización política por parte del franquismo.

En este sentido, Vázquez Montalbán considera a este locutor el inventor de un lenguaje radiofónico-futbolístico-nacional-sindicalista al servicio del Régimen. Sus narraciones épicas alimentaron un sentimiento patriótico alrededor del equipo nacional que alcanzó su cénit en el Mundial de Brasil (1950). El momento álgido de la trayectoria radiofónica de Matías Prats, guardado para siempre en la memoria de los españoles, fue la narración del gol conseguido por Zarra ante Inglaterra. Un tanto que clasificaba a España para las semifinales:

Cuando Zarra e Igoa consiguieron marcar el gol casi juntos, Matías Prats gritó como hubiera gritado el adolescente grumete de la nave almirante de la Invencible, si la Invencible no hubiera sido diezmada por las tempestades y por la flota inglesa. Aquel ¡GOL! de Matías Prats es el punto de origen del CONTAMOS CONTIGO, del desarrollo del turismo, del triunfo de Massiel en la Eurovisión, del trasvase del Tajo y el Segura, de las autopistas de peaje, del VII Plan de Desarrollo. ("Casi todo en technicolor", 33).

A tenor de la carga heroica y patriótica contenida en la retransmisión del periodista cordobés, Vázquez Montalbán interpreta la locución de 
este gol como un hito en la Historia de España. Un acontecimiento que se sitúa por encima del "A mí, Sabino, que los arrollo" de Belaúste en los Juegos de Amberes (1920) y que solo es superado por el "tierra a la vista" de Rodrigo de Triana ("Casi todo en technicolor", 33).

La dedicación de esta victoria internacional al dictador y el papel de su narración en la valoración patriótica del gol de Zarra contra Inglaterra permanecerán en la memoria del periodista barcelonés. En distintas ocasiones, recordará ambas efemérides para aclarar que los únicos éxitos de la selección española de fútbol se obtuvieron bajo presiones políticas o impulsos épicos. La primera, al considerar la ausencia de un delantero centro goleador en la selección española como el principal hándicap para el Mundial de Argentina de 1978 ("No tenemos delantero centro", 13). La segunda, a raíz de la celebración del Mundial de España en el año 1982 ("La imagen del mundial", 31). La tercera, en 1990, tras la eliminación en los octavos de final del Mundial de Italia ("En torno al patriotismo", 146). Y la última, en el 2000, para destacar que en diez años España únicamente había logrado ganar el campeonato olímpico de fútbol ("iViva el fútbol sala!", 114).

Matías Prats regresó a la pequeña pantalla como colaborador en la retransmisión de los partidos del Mundial de Argentina (1978). Durante una de sus intervenciones, acuñó un nuevo concepto futbolístico muy apropiado para un país que siempre está a punto de conseguir algo pero se queda a medio camino. El empate sin goles frente a Brasil dejaba prácticamente sin opciones de clasificación a la selección española. Pero este gran periodista, dispuesto a salir al rescate de la patria en cualquier momento, transformó este pésimo resultado en una "victoria moral" ("Matías Prats ataca de nuevo", 6).

Matías Prats reapareció, una vez más, en Radio Nacional como comentarista del partido entre el Real Madrid y el Liverpool. Al escuchar su voz por la radio, Vázquez Montalbán experimentó una regresión a los años cincuenta. En esa época, el locutor asumía la responsabilidad de crear la épica deportiva necesaria para distraer a los españoles y presentar los triunfos futbolísticos como conquistas políticas:

Prats puso lenguaje y metalenguaje (es decir, un lenguaje que lo es pero que no se nota que lo es) a la épica deportiva que fue distrayendo a los españoles de aplazamientos revolucionarios e imperiales. Revolución e imperio aplazados gracias a Matías Prats, los tercios futbolísticos de España o en su defecto del Real Madrid ponían la pica en Flandes y cuando no la ponían la 
culpa la tenía el género humano bajo la forma de árbitro o incluso de niño ("El retorno de Matías Prats", 39).

El periodista barcelonés citó en diversas ocasiones al locutor cordobés para denunciar el patriotismo exacerbado de los medios de comunicación españoles en torno al equipo nacional. En el decisivo partido entre España y Dinamarca, donde la selección se jugaba la clasificación para la fase final del Mundial de Estados Unidos (1994), los comentaristas recuperaron las antiguas alusiones a la furia española. Una expresión que parecía enterrada por el paso de los años y el cambio político (“España: pan y fútbol”, 112).

Algunos medios de comunicación afines al gobierno popular realizaron una valoración excesivamente optimista de las posibilidades que los deportistas españoles tenían de obtener medallas en los Juegos de Sydney (2000). Vázquez Montalbán compara esta estrategia mediática con la propaganda política del NO-DO que exageraba las capacidades de los españoles. Pero también con el patriotismo desproporcionado generado tras el gol marcado conjuntamente por Prats y Zarra a Inglaterra ("Medallas, medallas, medallas", 122). La recuperación del control político del país por parte de la derecha española supuso un cierto renacimiento del patriotismo nacional a través del fútbol. Una percepción que se confirmó durante las retransmisiones televisivas de los partidos de España en el Mundial de Corea y Japón (2002) al ver como los locutores teñían sus comentarios de un tono épico comparable al de Matías Prats ("Domingo 16", 73).

\section{El cabo Bernabéu}

Santiago Bernabéu está considerado el presidente más importante de la historia del Real Madrid. Un reconocimiento otorgado tanto por la duración de su mandato, treinta y cinco años, como por sus éxitos deportivos, ganador de seis Copas de Europa y numerosas ligas. Además, es uno de los dirigentes futbolísticos que más protagonismo tiene en la obra deportiva montalbaniana.

Esta relevancia no solo responde a su condición de representante del máximo rival del "Barça", sino, sobre todo, a su clara vinculación con el Régimen y a su particular relación con los catalanes. En el 39 formaba parte del ejército nacional que entró victorioso en Barcelona. La estrecha relación del presidente madridista con el franquismo será uno de los principales argumentos para entender la representatividad política adquirida por el club blanco durante este periodo histórico. Vázquez Mon- 
talbán destacará la implicación militar de Bernabéu refiriéndose a él como "un cabo". También insistirá en la peculiar identidad que esta vinculación del considerado mejor presidente de la entidad otorga al Real Madrid ("Se masca", última página).

Dentro del desarrollo del fútbol español tras la autarquía, el Real Madrid constituía una excepción. El resto de clubes dejaron de ser presididos por militares pasando a manos de importantes hombres de negocios deseosos de mayor presencia pública. En cambio, el club de la capital de España permaneció en manos de un cabo. De esta forma, se reforzaba el paralelismo entre el Real Madrid y el Estado español, ambos presididos por personas con un papel destacado en la Guerra Civil ("Els líders naturals", C2). En unos tiempos en que la Federación Española de Fútbol dependía directamente de la Secretaría General del Movimiento, las buenas conexiones existentes entre el presidente del Real Madrid y el gobierno franquista resultaron de gran ayuda en la resolución del caso Di Stéfano:

Y de pronto, como si se hubiera tratado de una aparición, la saeta rubia se esfumó y reapareció en Madrid, donde el cabo voluntario del ejército franquista, señor Bernabéu, liberador de Cataluña dominada por los rojos, tiraba de uno de los extremos de aquella saeta reclamándola para el Real Madrid ("Di Stéfano, Kubala, Suárez...”, 51).

Con motivo del "gurucetazo", 6 el periodista barcelonés insiste en la importancia de la figura de Bernabéu para el Régimen. Don Santiago fue el gran armador del equipo legendario, liderado por Di Stéfano, que consiguió ganar cinco Copas de Europa seguidas. Unos triunfos que ratificaron la voluntad imperial española aplazada desde hacía siglos. Era lógico que el franquismo le estuviera tan agradecido:

Don Santiago Bernabéu hizo del Real Madrid no un equipo regente, no un equipo real, sino un equipo imperial. Hombre dotado de espíritu de conquista, al frente de los tercios madridistas (eran los tiempos del tres, tres, cuatro) dejó en ridículo a Pedro Valdivia y a Hernán Cortés ("El Real Madrid”, 12).

La memoria de su entrada en Barcelona como cabo del ejército franquista provocaba que el público barcelonista relacionase su figura con la del

\footnotetext{
${ }^{6}$ Esta expresión se refiere al inexistente penalti señalado -a raíz de una falta cometida fuera del área- por el árbitro Emilio Guruceta en el partido de vuelta de los cuartos de final de la Copa del Generalísimo de 1970 contra el Real Madrid.
} 
conde-duque de Olivares (“Adiós a la liga. ¡Hala Madrid!”, 10-11). Con motivo del 75 aniversario del "Barça", Montalbán explica cómo el presidente madridista simbolizaba la represión del Estado contra la identidad nacional. Incluso era así para muchos catalanes que desconocían la historia de Cataluña: «No todos los catalanes saben, por ejemplo, quién era el conde duque de Olivares, y en cambio saben perfectamente quien es don Santiago Bernabéu» ("El Barça: bodas de diamante", 23). Tras la muerte de Franco, no salía de su asombro ante el intento del presidente madridista de borrar su vinculación con la Dictadura negando haber recibido alguna ayuda económica ("Bernabéu contra el régimen", 4).

Santiago Bernabéu presidió el Real Madrid hasta su muerte en 1978. A partir de ese momento, todas las referencias a su persona pretenderán mantener viva la memoria del significado del club durante el franquismo. Con motivo del partido entre el "Barça" y el Real Madrid disputado en el Camp Nou en febrero de 1980, el presidente de la Generalitat, Josep Tarradellas, acordó una reconciliación entre los mandatarios de ambos clubes. Este compromiso, acorde con una transición política pactada, se presentaba como una oportunidad para reparar los viejos agravios entre las dos entidades. Algunas de estas ofensas estaban vinculadas a las declaraciones de Santiago Bernabéu. El nuevo presidente del Real Madrid, Luis de Carlos, asumía la responsabilidad de limar las asperezas ("Cuarenta y un años de paz", 39). Diez años después del famoso 0 a 5 logrado por el "Barça" de Cruyff en el campo del Madrid, Vázquez Montalbán ofreció a Bernabéu el quinto gol de aquel partido: "iMeteros a Bernabéu donde os quepa! 5-0". Una dedicatoria en la que también aludía al orgullo del presidente blanco por haber participado en el ejército libertador de Cataluña ("Cuando el Real era algo más que un club", 6).

El gobierno de José María Aznar intentó recuperar al Real Madrid como adalid del Estado. Una voluntad que, en opinión de Montalbán, apenas alcanzaba el nivel de las connotaciones históricas y políticas de los tiempos de Bernabéu (La aznaridad, 159). La elección de Florentino Pérez, un hombre de negocios enriquecido rápidamente gracias a la construcción, supuso una nueva oportunidad para recordar el vínculo que el club tuvo con el franquismo a través de su presidente. El proyecto de este empresario alejaba considerablemente al equipo blanco del significado adquirido cuando el cabo Bernabéu se enorgullecía de haber ocupado Cataluña a las órdenes del general Muñoz Grandes ("La mayoría absoluta", 80). Sin embargo, este simbolismo político del Real Madrid, vinculado al antiguo mandatario merengue, no desaparecerá del sentimiento del público culé ni del paisaje emocional montalbaniano. En el 
año 2002, ambos equipos se enfrentaron en la semifinal de la Copa de Europa. La posibilidad de una derrota barcelonista le permitió reflexionar de nuevo sobre el paralelismo histórico entre las derrotas políticas de Cataluña y las futbolísticas del "Barça" contra el equipo de Bernabéu ("Por los siglos de los siglos", 52).

\section{El incombustible Pablo Porta}

Pablo Porta fue nombrado presidente de la Real Federación Española de Fútbol en 1975 por Fernando Herrero Tejedor, Ministro Secretario General del Movimiento. Después de la muerte de Franco, volvió a ser ratificado "democráticamente" pese a ser el único candidato. Vázquez Montalbán no prestó demasiada atención al nuevo presidente federativo hasta que leyó un informe sobre su pasado franquista realizado por el periodista Joaquín Ibarz. En los años cuarenta, Pablo Porta había dirigido la represión contra los estudiantes de ideología republicana. A la vista de los hechos descritos por algunos de los compañeros y de las víctimas del presidente, Montalbán lamenta, irónicamente, que esa "eficacia organizativa" no la demuestre en su actual cargo "democrático":

Según el reportaje, el joven Porta era el jefe, el caudillo de la situación y practicaba la dialéctica de los puños y las pistolas con una eficacia organizativa muy superior a la que ha demostrado al frente de la Federación Española de Fútbol. Esperamos con alborozo la segunda parte del Informe Ibarz y la capacidad de respuesta del Sr. Porta, flamantemente elegido primer presidente democrático de la Federación Española de Fútbol ("El pasado de Pablo Porta", 7).

A pesar de este escándalo público, el presidente de la Federación decidió seguir en su puesto. Una estrategia acorde con el espíritu pactista y desmemoriado de la transición. Además, evitó la polémica sobre unas "elucubraciones" periodísticas, dejando el tema en manos de sus abogados. El escritor barcelonés considera una cuestión de memoria histórica y de higiene mental colectiva juzgar al responsable de unos hechos tan siniestros. Aunque, en caso de ser condenado por un tribunal, siempre podría acogerse a una de las amnistías ("Los felices cuarenta de don Pablo Porta", 41).

A parte de las actuaciones judiciales derivadas del informe publicado por Ibarz, Vázquez Montalbán decide adherirse a las peticiones para la dimisión de Pablo Porta. Una persona con un pasado vinculado directamente al franquismo no era la más adecuada para llevar a cabo la refor- 
ma democrática que requería la Federación. El cese de su cargo al frente del fútbol español se convertirá en uno de los caballos de batalla montalbanianos durante la Transición. Incluso llegará a reclamar al presidente barcelonista Agustín Montal que el club, en virtud de su representatividad nacional, se añada a este clamor popular en Cataluña ("Porta dimite, la democracia no te admite", 5).

$\mathrm{Al}$ margen de las presiones de algunos clubes, el presidente de la $\mathrm{Fe}$ deración Española de Fútbol contaba con el apoyo incondicional y la "solidaridad" del resto de presidentes federativos. Una muestra de gratitud hacia la persona que les había situado al frente de estas instituciones. Así se evidenciaba, una vez más, la dificultad para cambiar las estructuras de las organizaciones deportivas heredadas del franquismo ("Las federaciones dieron el portazo", 4). No obstante, Montalbán siguió insistiendo en la denuncia de la "extraordinaria" habilidad de Pablo Porta para mantenerse en el cargo más allá de sus vínculos con el franquismo ("No tenemos delantero centro", 13).

En la sección "Productos y derivados" de la revista Por Favor aparecen diversas alusiones a la gestión de Porta con motivo del Mundial de Argentina (1978). En primer lugar, denuncia el estatus económico y social que ha adquirido gracias al fútbol. Después critica los apoyos políticos que mantiene pese a su mala gestión. Y, finalmente, recuerda su pasado político represivo durante el franquismo ("Productos y derivados de: fútbol", 7).

Montalbán atribuyó la excelente relación entre Kubala, seleccionador nacional, y el presidente de la Federación a su oposición al comunismo. Antes del partido contra Rumanía, Kubala insinuó el peligro de una posible transformación comunista de España con la llegada de la democracia en la charla a sus jugadores. Unas palabras comprensibles proviniendo de un "fugitivo del terror rojo" acogido por el franquismo. Sin embargo, Kubala debía saber que el régimen fascista al que estaba tan agradecido también perseguía "terriblemente" a los comunistas. Así como que su gran amigo era uno de los encargados de esta represión ("Kubala, un ideólogo", 14).

La inclusión de una entrevista con Pablo Porta en el libro Mis almuerzos con gente inquietante ratifica la importancia de este personaje en la obra deportiva montalbaniana. Seguramente la "inquietud" que le provocaba estaba relacionada con la pervivencia en las instituciones democráticas de personas estrechamente vinculadas al franquismo. Montalbán no elude ninguna cuestión, por muy polémica que pueda parecer, 
e incluso le pregunta sobre su militancia en el SEU franquista, conocido como "la checa de Porta" (182-190).

\section{El desencanto barcelonista}

Pese a estar siempre pendiente de los resultados de su equipo, Vázquez Montalbán no siempre aprueba la trayectoria de la institución. Fue especialmente crítico con ella durante la presidencia de José Luis Núñez (1978-2000), un periodo donde su significación política y social quedó relegada a un segundo plano. En una conversación informal junto a otros dos escritores culés, admitía que, últimamente, no vivía su pasión culé tan intensamente como antaño. Un estado anímico relacionado no solo con la edad, sino también con que se había apoderado de él un cierto desencanto con el club ("Barça i integració", 139).

Su afición barcelonista responde, por un lado, a la admiración despertada por algunos grandes jugadores -Kubala - y algún gran equipo -el Barça de las cinco copas-. Pero también a la afinidad ideológica y política que siente hacia una entidad derrotada por el franquismo y que asume la defensa de una identidad catalana integradora. El cambio de rumbo del club tras la llegada a la presidencia de Núñez erosiona este vínculo:

Yo soy del Barça de mi infancia y no de éste. Creo que el Barça es algo más que un club, durante mucho tiempo ser del Barça era una declaración de principios de la catalanidad (Jover 1984).

Bajo la dirección de este constructor, el Barça renuncia a la identificación con un catalanismo popular y se convierte en un negocio. A partir de este momento, la prioridad consiste en cuadrar los balances económicos y ganar el máximo número de títulos posibles:

Eso estaba allí cuando nosotros empezamos a teorizar sobre la cuestión, dentro de la estética pop del final de la década de los sesenta y buena parte de ese barcelonismo simbólico se sintió agredido cuando llegó el nuñismo y empezó a desideologizar el club y a convertirlo en una inmobiliaria ("Como si la directiva y el Real Madrid no existieran”, 4).

Durante los primeros años de su mandato, Montalbán intenta denunciar esta voluntad de desposeer al club de la representatividad social y política adquirida durante el franquismo. Un simbolismo que lo convertía en una institución fundamental para conseguir la tan anhelada democracia. Por eso, insiste en preservar el significado político y social del club. En 1979 la directiva promovió una campaña para lograr el 
apoyo del público al equipo en el partido contra el Real Madrid. Una iniciativa atribuible a la urgencia de conseguir resultados cuando se abandona la representatividad extradeportiva del club:

Hay quien da una interpretación política a los desastres azulgranas, como ya hay democracia y Generalitat, el Barça ha dejado de ser algo más que un club. Si ha dejado de ser algo más que un club no es por culpa de la democracia y de la Generalitat, sino por una determinada filosofía de gestión introducida por el señor Núñez (“Salven el Barça!”, 13).

Un año después, y otra vez con motivo de un enfrentamiento contra el club blanco, recuerda al presidente que cuando el equipo ganaba títulos en los años cuarenta y cincuenta ya era considerado "más que un club" ("Más que un club", 12). Descalifica así el argumento empleado por los dirigentes que buscaban aferrarse al significado identitario del club para justificar sus derrotas.

A propósito de la disputa electoral con el candidato Sixto Cambra en 1988, llega a la conclusión de que el club tiene simplemente el presidente que se merece, justificando así su decisión de no intervenir en dichas elecciones. El "Barça" ya no responde al mito con el que creció. Un simbolismo construido en tiempos donde se necesitaba la imaginación para sublimar las esperanzas de un pueblo derrotado:

Aunque cada vez sé menos lo que digo cuando pronuncio la palabra Barça, porque poco tiene que ver la entidad actual con la colección de cromos o con la comunión de los santos que nos hizo barcelonistas ("Adiós, Barça, adiós", 64).

Por otro lado, las manifestaciones masivas después de los triunfos barcelonistas tampoco adquieren el carácter reivindicativo de otras épocas y se han convertido en una excusa para el vandalismo juvenil:

Muchos de los que nos alegramos por las victorias del Barça lo hacemos en nombre de un Barça que tenemos en la memoria, y la mayor parte de los que utilizan al Barça para liberarse de su mala leche histórica no tienen otro sentido histórico que el que les proporciona el Barça. El sentido de la historia para ellos es que el Barça gane y el Madrid pierda, y cuando ocurre lo contrario ni la historia ni sus vidas tienen sentido ("Nueve días y medio", 27). 
El periodista barcelonés también lamenta como incluso sus propias afirmaciones sobre el significado político del barcelonismo en la lucha contra el centralismo quedan desvirtuadas en boca de entrenadores extranjeros que ya no saben qué hacer para conseguir el apoyo del público ("El sofriment", 20). Tampoco los jugadores foráneos demuestran el compromiso de antaño con el club, convertido simplemente en la entidad que les paga. Así, en caso de incumplimiento por parte del club de sus obligaciones contractuales amenazan con dejar el equipo, como sucedió con el brasileño Rivaldo ("Rivaldo", 15).

La conocida como Ley Bosman, que reconocía el derecho de los futbolistas trabajar sin restricciones en cualquier equipo europeo, posibilitó la llegada masiva de jugadores extranjeros al fútbol español. Este nuevo marco jurídico cuestionaba un imaginario mítico basado en la identificación con el club a través de los jugadores nativos. Un argumento más para mostrar su desencanto:

Confieso que me empieza a importar un pepino la extranjería que se ha apoderado de nuestros clubes y que me siento progresivamente liberado del compromiso emocional mitológico que en algún momento de mi infancia adquirí con mi equipo de fútbol ("Nada será igual después de París", 114).

La "quinta del Mini", un grupo de jugadores de la cantera capitaneados por Iván de la Peña, constituía su última esperanza para la recuperación del imaginario barcelonista de su infancia. Pero el entrenador holandés Louis Van Gaal, obsesionado por acabar con cualquier herencia cruyffista y empeñado en fichar compatriotas suyos, acabó con esta generación de futbolistas:

Cada vez que escucho la alineación del Barcelona por los altavoces del Camp Nou tengo la sensación de que me han cambiado de estadio, de país, de ropa interior y de piel ("Por los siglos de los siglos", 52).

Cuando en abril de 2002 se disputa la semifinal de la Copa de Europa entre el F. C. Barcelona y el Real Madrid, su fe en el simbolismo del club ya estaba muy debilitada ("Por los siglos de los siglos", 52). Las elecciones a la presidencia celebradas en el año 2003, sin la presencia de Núñez ni de Gaspart, consituirán una nueva oportunidad para reflotar los valores del barcelonismo: 
Confío en que esta vez acabarán mis sufrimientos como seguidor barcelonista, iniciados el día en que, victorioso Núñez, las oraciones compuestas desaparecieron del lenguaje oficial del club ("Lo que bien se concibe bien se expresa...", 54).

Una transformación que, como lamenta su hijo Daniel, no pudo contemplar con sus propios ojos (Recuerdos sin retorno, 133-134).

\section{La crónica futbolística: memoria política y sentimental}

Como intelectual de izquierdas, Vázquez Montalbán lamenta cierta miopía que únicamente es capaz de percibir en la afición futbolística una veleidad alienante. Con esta mirada sesgada se ha ampliado la brecha que separa la cultura popular de la cultura de élite y los pensadores progresistas pierden una excelente oportunidad para acercarse a la gente.

Montalbán elabora una hermenéutica del fútbol emancipada del oficialismo de la retórica marxista. Rechaza los postulados dogmáticos y crea un pensamiento propio acorde con su percepción de la realidad. Se aleja, pues, de los tópicos sostenidos por los intelectuales de partido. No obstante, asume la esencia del marxismo al prescindir de especulaciones estériles y centrarse en el análisis de lo real. Una reflexión que no responde a un interés teórico y erudito, sino a la voluntad de transformar las condiciones sociales.

Aplicando una perspectiva subcultural, concede al fútbol la función de ser una de las pocas formas de participación social al alcance del pueblo. Reivindica su fuerza como configurador de una sentimentalidad popular. Asimismo, defiende la compensación futbolística como la única alternativa posible para reducir la conflictividad ante la persistencia de las desigualdades sociales y el déficit de proyectos de futuro. Su fuerza mítica se convierte en una de las escasas oportunidades para los perdedores sociales de experimentar el triunfo, sobre todo en el contexto de la Posguerra.

El recuerdo y la memoria son el antídoto frente a una manipulación ideológica que pretende soslayar los aspectos denunciables del pasado, sobre todo en relación con el franquismo. Esta tergiversación de la historia será llevada a cabo, primero, por la censura y la propaganda franquista. Luego, por el pacto de silencio propio de la transición. Y, finalmente, por el olvido democrático y posmoderno.

La reivindicación de la memoria histórica del franquismo a través del fútbol se convertirá en uno de los ejes del discurso montalbaniano. Insis- 
te en recordar los vínculos con el régimen franquista de dirigentes futbolísticos -Pablo Porta o Santiago Bernabéu- y de algunas instituciones -el Real Madrid o la Federación Española de Fútbol-.

Pero la reivindicación del pasado no solo responde a un interés ideológico. También pretende recuperar el valor de unas vivencias colectivas y personales que están siendo sepultadas por el tiempo. Vázquez Montalbán asume el compromiso de conservar y expresar una memoria personal y colectiva. En tanto que autor procedente de los estratos sociales más bajos, considera que tiene la responsabilidad de emplear la escritura para inmortalizar una sentimentalidad popular donde el fútbol ocupaba un lugar destacado.

\section{Bibliografía}

ACEC. Manuel Vázquez Montalbán [DVD]. Barcelona: ACEC, 2003.

Aranda, Quim. Què pensa Manuel Vázquez Montalbán. Entrevistat per Quim Aranda. Barcelona: Dèria Editors, 1995. Impreso.

Benjamin, Walter. Tesis sobre la historia y otros fragmentos. México: Itaca. UCAM, 2008. Impreso.

---. "Juguetes antiguos". Obras IV. Vol. I. Madrid: Adaba, 2006. Impreso.

Colmeiro, José. "El intelectual en la cultura: entrevista con Manuel Vázquez Montalbán". Crónica del desencanto: la narrativa de Manuel Vázquez Montalbán. Florida: Nort South Center Press, University of Miami, 1996. 269-291. Impreso.

Colomer, Josep. Els estudiants de Barcelona sota el franquisme. Barcelona: Proa, 1978. Impreso.

Erba, Roberta. Los pseudónimos de Vázquez Montalbán. Obtenido el 20 de Enero de 2011. Sitio web: http://www.vespito.net/mvm/seudo.html.

Espadaler, Anton M. "Entrevista a Joaquim Molas". El País, Quadern, 14 Enero, 1999: 8. Impreso.

Jover, José L. (dir.). Manuel Vázquez Montalbán: un viejo columnista [video]. Madrid: Radio Televisión Española, 1984. Vídeo.

López Doy, Luis (dir.). Manuel Vázquez Montalbán: El éxito de un perdedor. Madrid: Televisión Española, 1997. Vídeo.

Salgado, Francesc. La construcció de la identitat periodística de Manuel Vázquez Montalbán. De la censura a la transició (1960-1978). Barcelona: Universitat Pompeu Fabra, 2009. (Tesis doctoral inédita). Impreso.

Tyras, George. Geometrías de la memoria. Conversaciones con Manuel Vázquez Montalbán. Granada: Zoela, 2003. Impreso. 
Vázquez Montalbán, Manuel. "Casi todo en technicolor". Triunfo, 20 Septiembre, 1969: 29-35. Impreso.

---. "Cuando Di Stefano y Kubala llenaban los estadios". Triunfo, 27 Septiembre, 1969: 29-35. Impreso.

---. "Los felices sesenta". Triunfo, 4 Octubre, 1969: 35-40. Impreso.

---. "Barça! Barça! Barça!”. Triunfo, 25 Octubre, 1969: 23-28. Impreso.

---. "El Real Madrid", TeleleXpres, 11 junio, 1970: 12. Impreso.

---. "Barça, Barça, Barça". Barça, 30 Marzo, 1971: sin paginar. Impreso.

--- "Arqueologia i subcultura". Joan Josep Artells. Barça, Barça, Barça: F. C. Barcelona, esport i ciutadania. Barcelona: Laia, 1972: 7-9. Impreso.

---. “Adiós a la Liga. ¡Hala Madrid!”. Triunfo, 27 Mayo, 1972: 10-12. Impreso.

---. "Lo intocable y lo innombrable". Triunfo, 30 Junio, 1973: 10. Impreso.

---. "El Barça: bodas de diamante". Triunfo, 30 Noviembre, 1974: 22-23. Impreso.

---. "El pasado de Pablo Porta". Por Favor, 27 Diciembre, 1976: 7. Impreso.

---. "Los felices cuarenta de don Pablo Porta". Triunfo, 8 Enero, 1977: 41. Impreso.

---. "Las federaciones dieron el portazo". Por Favor, 28 Febrero, 1977: 4. Impreso.

---. "Bernabéu contra el régimen". Por Favor, 11 Julio, 1977: 4. Impreso.

---. "No tenemos delantero centro". La Calle, 6 de junio, 1978: 13. Impreso.

---. "Productos y derivados de: fútbol". Por Favor, 12 Junio, 1978: 7. Impreso.

---. "Matías Prats ataca de nuevo". Por Favor, 19 Junio, 1978: 6. Impreso.

---. "Salven el Barça!". El Periódico, 16 Febrero, 1979: 13. Impreso.

---. "Kubala, un ideólogo". La Calle, 10 Abril, 1979: 14. Impreso.

---. "Más que un club". El Periódico, 9 Febrero 1980: 12. Impreso.

---. "Cuarenta y un años de paz". El País, 12 de febrero, 1980: 39. Impreso.

---. "El retorno de Matías Prats". El Periódico, 30 Mayo, 1981: 39. Impreso.

---. "La imagen del Mundial". El Periódico, 24 Mayo, 1982: 31. Impreso. 
---. Mis almuerzos con gente inquietante. Barcelona: Planeta, 1984. Impreso.

---. "Cuando el Real era algo más que un club". El País, Deportes, 13 Febrero, 1984: 6. Impreso.

---. “Se masca...”. El País, 13 Mayo, 1985: última página. Impreso.

---. "Porta dimite, la democracia no te admite". Por Favor, 10 Enero, 1987: 5. Impreso.

--- "Nueve días y medio". El País, 20 Mayo, 1989: 27. Impreso.

---. "En torno al patriotismo". Interviú, 18 Julio, 1990: 145-146. Impreso.

---. "Como si la directiva y el Real Madrid no existieran". El País, Deportes, 13 Mayo, 1991: 4. Impreso.

---. Barcelonas. Barcelona: Empúries, 1992. Impreso.

---. "Credo": El País, Deportes, 21 Mayo, 1992: 54. Impreso.

---. "España: pan y fútbol”. Interviú, 29 Noviembre, 1993: 112. Impreso.

---. "La memòria històrica". Avui, 6 Mayo, 1995: C2. Impreso.

---. "Els líders naturals". Avui, 1 Julio, 1995: C2. Impreso.

---. "Los tradicionales lazos de enemistad". El País Semanal, 28 Abril, 1996: 81. Impreso.

---. "El sofriment". Avui, 19 Abril, 1997: 20. Impreso.

---. La literatura en la construcción de la ciudad democrática. Barcelona: Crítica, 1998. Impreso.

---. "Nada será igual después de París". Interviú, 8 Junio, 1998: 114. Impreso.

---. "Barça i integració". AAVV. Amb blau sofert i amb grana intens. Cent anys del Barça. Barcelona: Proa, 1999: 135-157. Impreso.

---. "Adiós, Barça, adiós". El País, 13 Octubre, 1999: 64. Impreso.

---. "Medallas, medallas, medallas". Interviú, 2 Octubre, 2000: 122. Impreso.

---. “`Viva el fútbol sala!”, Interviú, 5 Marzo, 2001: 114. Impreso.

---. "Rivaldo". Avui, 11 Agosto, 2001: 15. Impreso.

---. "Por los siglos de los siglos". El País, 23 Abril, 2002: 52. Impreso.

---. "La mayoría absoluta". El País Semanal, 23 Abril, 2002: 80-81. Impreso.

---. "Domingo 16". El País, 15 Junio, 2002: 73. Impreso.

--- La aznaridad. Por el imperio hacia Dios o por Dios hacia el imperio. Barcelona: Mondadori, 2003. Impreso.

---. "Tot el camp és un clam!". Avui, 14 Junio, 2003: 21. Impreso.

---. "Lo que bien se concibe bien se expresa...". El País, 14 Junio, 2003: 54. Impreso. 
---. "Di Stéfano, Kubala, Suárez...". El País, 22 Septiembre, 2003: 51. Impreso.

Vázquez Sallés, Daniel. "Manuel Vázquez Montalbán: el fabulador de la memoria”. José F. Colmeiro (ed.). Manuel Vázquez Montalbán: el compromiso con la memoria. Woodbrige: Támesis, 2007: xi-xii. Impreso.

---. Recuerdos sin retorno. Barcelona: Península, 2013. Impreso.

Villena, Miguel A. "Mucho más que deporte". El País, Babelia, 9 Abril, 2005: 13. Impreso. 